\title{
Physiologic Basis for Focal Motor Seizures and the Jacksonian "March" Phenomena
}

\author{
JOHN T. MURPHY, HON C. KWAN, W.A. MacKAY, and YIU C. WONG
}

\begin{abstract}
SUMMARY: Mechanisms underlying focal motor seizures and the Jacksonian "march" have been explored on the basis of recent physiologic data concerning the "nested ring" spatial and functional organization of motor cortex. Focal motor seizures can be understood in terms of the focal representation at motor cortex of elements controlling movement of a limb part about a single joint. The preponderance of three foci of origin of motor seizures, first reported by Hughlings Jackson, are related to lower thresholds of excitability at these loci, as demonstrated for forelimbs in the case of subhuman primates, and to the resultant bias of peripheral and central inpul to activate these loci. The "march" phenomenon which typically involves specific patterns of spread in the forearm. is
\end{abstract}

RESUME: Nous avons étudié les mécanismes sous-tendant l'épilepsie motrice focale et la "marche" Jacksonnienne à la lumière des données physiologiques récentes concernant l'organisation spaciale et fonctionnelle du cortex moteur. Les crises motrices focales peuvent s'expliquer en fonction de la représentation focale au cortex moteur des éléments qui contrôlent le mouvement d'un membre autour d'une articulation unique. La prépondérance de trois foyers d'origine des crises motrices, tel que rapporté par $H$. Jackson, serait en rapport avec les seuils diminués d'excitabilité à ces foyers, tel que démontré pour les membres antérieurs chez les primates subhumains, et avec le biais en faveur de ces sites par les influx périphériques et centraux. Le phénomène de "marche" (progression), qui typiquement implique des patterns spécifiques de diffusion aux explained in terms of the recently discovered nested ring organization. Thus the centrifugal spread of excitation from a particular locus in motor cortex would demand the pattern of spread of convulsive movements generally observed in clinical situations. The latter involves spread from face or leg to shoulder, forearm, then to hand, or conversely.

The physiological basis of activation and/or inhibition of focal motor epilepsy by peripheral stimuli is also now available on the basis of current experimental evidence. Thus the point to point coupling of periphery and motor cortex as defined in terms of control of limb parts about single forelimb joints, provides a substantial understanding of many of the clinical events sometimes termed "reflex" epilepsy.

avant-bras, s'explique par l'organisation en anneau enfoncé récemment découverte. Ainsi la diffusion centrifuge de l'excitation à partir d'un site particulier du cortex moteur exigerait le pattern de diffusion des mouvements convulsifs que l'on observe généralement dans les situations cliniques: donc diffusion du visage ou de la jambe vers l'épaule, l'avant bras et la main, ou inversement.

Grâce aux expériences récentes nous comprenons maintenant la base physiologique de l'activation et /ou de l'inhibition de l'épilepsie motrice focale par les stimuli périphériques. Ainsi plusieurs des évènements qualifiés en clinique d'épilepsie réflexe" s'expliquer par la relation point à point entre le cortex moteur et la périphérie, si on définit cette relation en fonction du contrôle des sections d'un membre autour d'une articulation unique.
From the Department of Physiology, University of Toronto.

Reprint requests to: Dr. John T. Murphy, Department of Physiology, Medical Sciences Bldg., University of Toronto, Toronto, Ontario, Canada M5S IA8.

\section{INTRODUCTION}

The careful clinical descriptions of Hughlings Jackson concerning focal motor epilepsy and the "march" phenomena which bear his name were of considerable heuristic value to following generations of neurophysiologists and clinical neuroscientists. Thus, a number of important animal and human experiments were done which provided evidence for the localized representation of movement functions in cerebral cortex (Asanuma, 1975; Ferrier, 1876; Fritsch and Hitzig, 1870; Leyton and Sherrington, 1917; Penfield and Boldrey, 1937; and Schafer, 1900). To these physiological studies were added further detailed clinical descriptions (Holmes, 1927; Penfield and Erickson, 1941; Walshe, 1943) which served to confirm and generalize the observations of Jackson. However, despite the considerable experimental and theoretical interest in this subject, attempts to provide a cogent physiologic basis for the observed clinical phenomena were largely unsuccessful (cf. Walshe, 1943). Part of the reason for this undoubtedly lay in the fact that surface stimulation of motor cortex in man (Penfield and Boldrey, 1937) and in subhuman primates (Woolsey et al., 1952) yielded maps which, although largely compatible with the observed clinical events, were not sufficiently fine grained in their detail to allow definite conclusions as to underlying mechanisms.

The recent demonstration of a "nested ring" spatial organization of motor cortex in subhuman primates by means of single unit recording and intracortical microstimulation (ICMS) techniques (Murphy et al., 1978) makes it now appropriate to reevaluate the question of the physiological basis for focal motor seizures and the Jacksonian "march" pheno- 
mena. Important facets of this problem include the following: functional localization in motor cortex, motor cortical activities during normal movement (the physiologic march) and pathologic movement (the epileptic march), and the influences of peripheral stimuli on motor cortical activities as these relate to seizure events. These aspects will be discussed in sequence, insofar as they pertain to present understanding of organization and function in the motor cortex. The relationship between clinical phenomenology and the "nested ring" model of motor cortex will be stressed particularly. Detailed literature reviews relating to the physiologic observations to be discussed in this paper have been presented elsewhere (Kwan et al., 1978; Murphy et al., 1978; and Wong et al., 1978) and will not be repeated.

\section{Functional Localization:}

The Representation Problem

This subject has at times been discussed as a "muscles versus movements" problem (cf. Phillips, 1975). Firm conclusions have been encumbered by ambiguity in the operational definitions employed by various authors. For example, a fundamental ambiguity resides in the meaning of the term "representation". The present evidence is that any of the following may be "represented" depending on how one defines the elemental operational unit of motor cortex: complex movements (Leyton and Sherrington, 1917), elementary movements (Kwan et al., 1978), multiple muscles (Fetz \& Finocchio, 1975), single muscle activity (Asanuma, 1975) and possibly even single motor unit activity. Pertinent literature on this topic has been reviewed recently (Kwan et al., 1978).

The elementary operational unit may be single neurons in motor cortex, or various combinations of these neurons. There is now evidence, from the use of ICMS, that activation of horizontal clusters of vertical aggregates of motor cortical cells can engender elementary movements about a single joint (Kwan et al., 1978). Moreover, as other horizontal clusters of different functions are activated, a variety of complex movements are possible either simultaneously or sequentially (Murphy et al., 1978). As

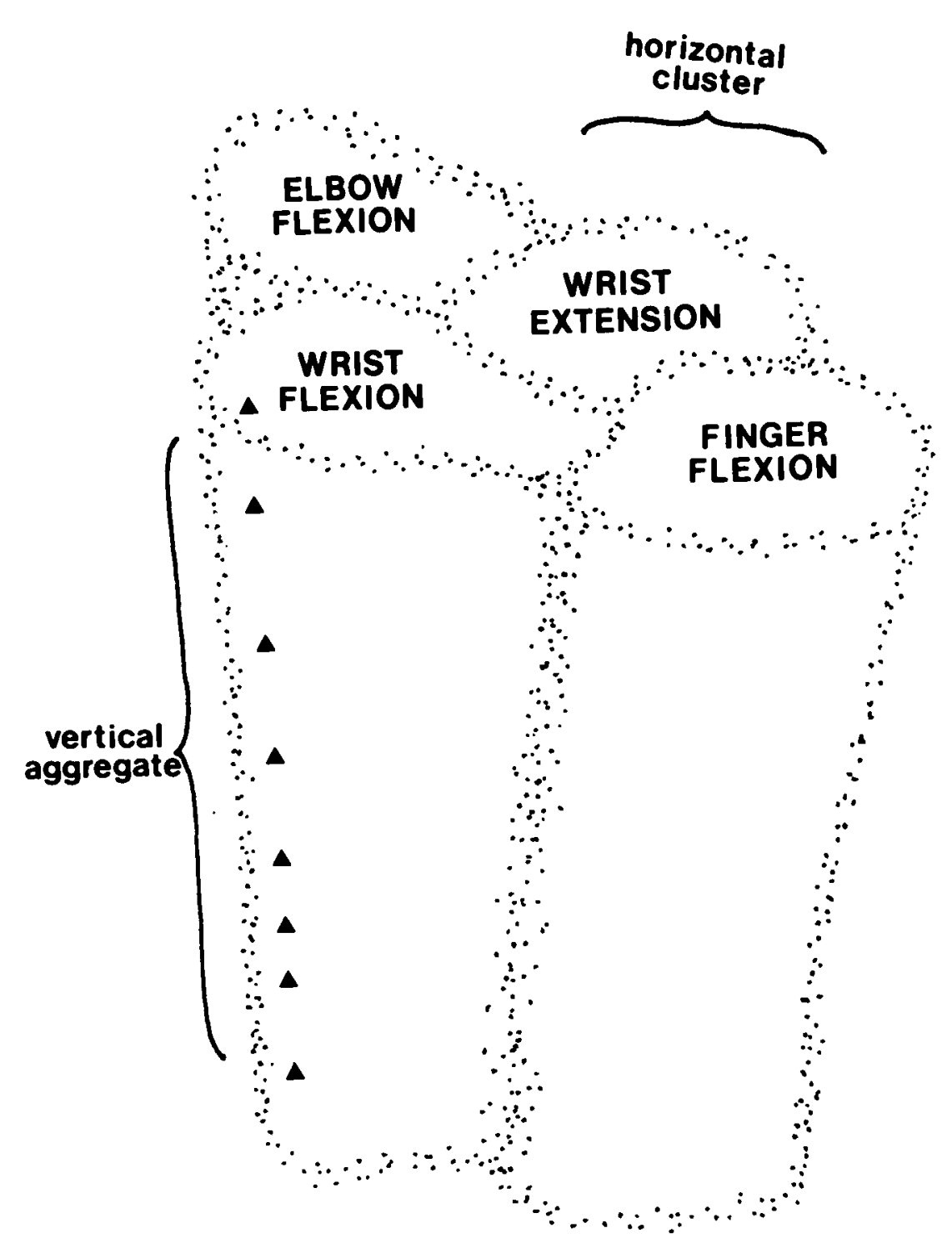

Figure $I$ - Vertical aggregates of single neurons (filled triangles) are arranged in orthogonal relation to the cortical surface. These neurons respond to cutaneous and/or proprioceptive input derived from the wrist joint or its surround (Wong et al., 1978). Intracortical micro stimulation (ICMS) at the loci of these neurons produces wrist flexion. Other vertical aggregates with similar properties are conjoined to form an irregularly shaped horizontal cluster which functions to produce wrist flexion. This cluster is adjacent to other clusters with different functions for the same joint, i.e. wrist extension, or with functions involving other, contiguous joints. These clusters range up to $2 \mathrm{~mm}$ at their largest dimension.

indicated above, selection of a different elementary operational unit will result in a different "representation" in motor cortex.

Figure 1 shows examples of such vertical aggregates and horizontal clusters. The existence of such functionally specific neuronal populations has been established for the upper limb in subhuman primates by means of
ICMS and passive sensory examination (Wong et al., 1978; Kwan et al., 1978; Murphy et al., 1978). Moreover, the behavior of single neurons within such vertical aggregates has been studied in the context of voluntary movement and found to be preferentially related to voluntary movement of the appropriate limb part about a single joint (Murphy et al., 1979; 


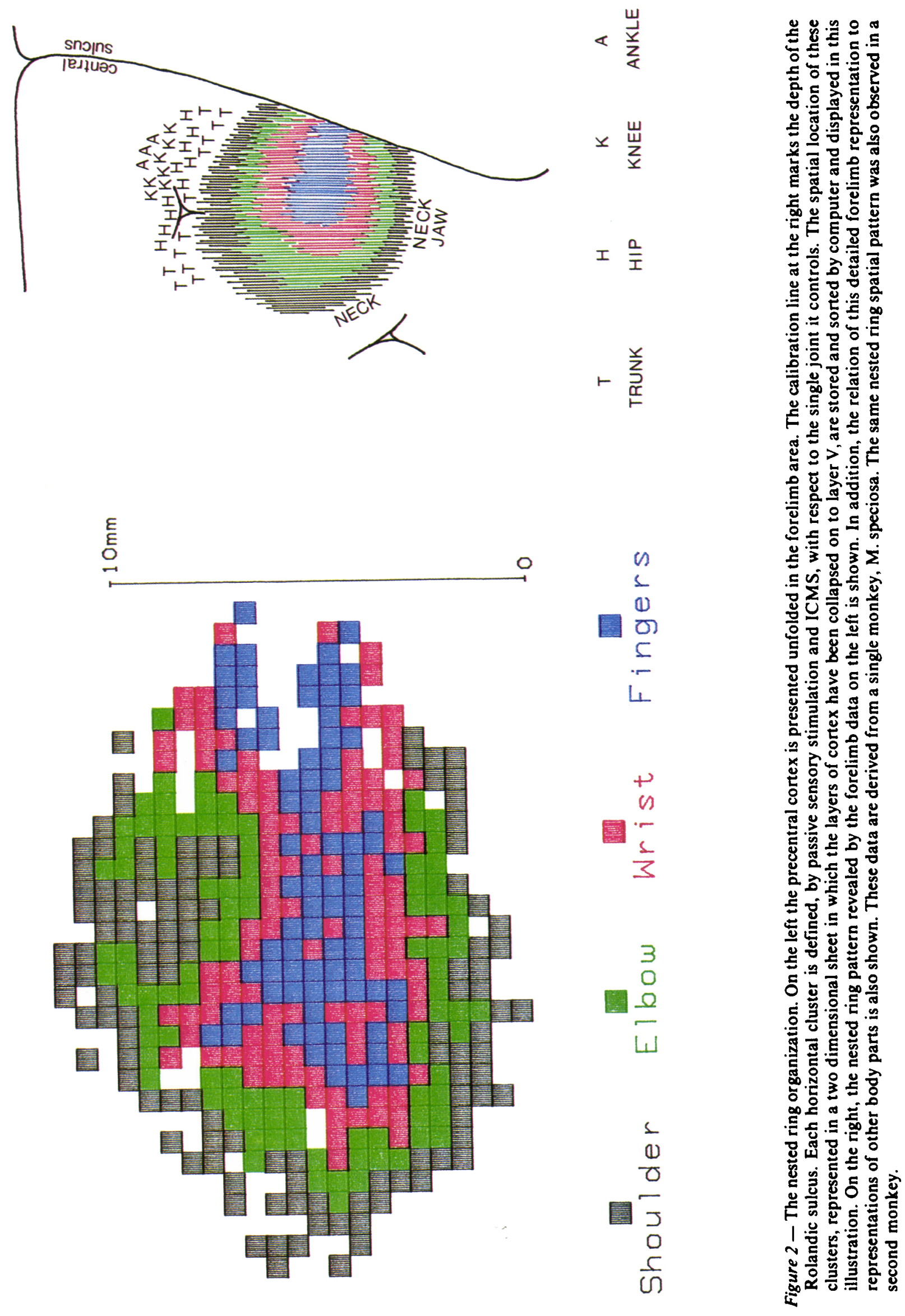


Wong et al., 1979a \& b). Hence, a satisfactory basis now exists to understand focal motor seizures involving convulsive movements about a single joint, and as well the related focal paresis which may occur.

As described by Gordon Holmes (1927), the initial stage of such focal motor seizures often involves clonic movements which may spread slowly and thus remain limited to one segment for a considerable time, enabling careful observation and study. These clonic movements "... consist of brisk tetanic contractions of all the muscles that cooperate in the movement ...". The second stage is one of motor paresis following the clonic movements. Holmes also called attention to the fact that the convulsive attacks may occasionally be replaced by transient paresis of that portion of the limb which in other attacks is involved in the clonic spasms. One may readily envision the activation or inactivation of vertical aggregates (Fig. 1) in the course of such focal convulsive activity or paresis, respectively.

One interesting aspect of the seizure activity as discussed by Jackson and subsequently confirmed (Walshe, 1943) concerns the preferred site of origin of focal seizures. Jackson revealed that there were "... three parts where fits of this group mostly begin: (1) in the hand; (2) in the face, or tongue, or both; (3) in the foot ..." (cf. Jackson, 1958, p. 68). In the case of the forearm, it has now been established in primates that the threshold for activation by ICMS of single joints is lowest for fingers and hand, and highest for shoulder, with the elbow intermediate (Kwan et al., 1978). This threshold differential readily explains the preferred site of origin of seizure activity in the case of the forelimb. If a similar threshold differential is found to exist in the case of the lower limb and the head, as would seem likely, a similar explanation may be invoked. Also of possible relevance to this phenomenon is the fact that those vertical aggregates subserving the fingers are concentrated in a central core, whereas those for the wrist, elbow and shoulder are situated in concentric rings surrounding this core (Fig. 2). Thus, one might expect that a particular pathologic process of solitary nature such as vascular occlusion of a small artery, scarring, or other disease entity, would be more prone to affect a large proportion of tissue in the central core and be less likely to affect a corresponding proportion of cortical tissue in the rings. This spatial organization would tend to act in concert with the observed threshold differential to produce the preferred sites or origin of focal motor seizures which are observed.

\section{Normal Movement: \\ The Physiological "March"}

As indicated above neurons with capacity to contribute to the production of elementary movements about single joints, when activated by ICMS, are located in vertical aggregates in motor cortex (Fig. 1). Extensive mappings of motor cortex have been carried out in this experimental context in subhuman primates ( $\mathrm{K}$ wan et al., 1978). When all aggregates in a particular monkey are typed with respect to single joints (fingers being lumped together as a single joint for convenience), and sorted by computer, the spatial pattern shown in figure 2 on the left emerges. It can be seen that a central core extending down into the Rolandic sulcus incorporates finger neurons, and this is encircled and interdigitated with successive concentric rings incorporating wrist, elbow, and shoulder aggregates, respectively. This concentric ring pattern is idealized in figure 2 on the right.

Because various patterns of joint position are inculcated in the activation of these vertical aggregates contained in the central core and nested concentric rings, the particular movement produced in any given situation would be a simple function of those aggregates which are activated. For example, a wrist extension aggregate may be located adjacent to a wrist flexion aggregate (Fig. 1). If only one of these two aggregates are activated, then extension or flexion would be expected. If both are activated, cocontraction and fixation at the wrist would be expected. A similar situation exists with respect to the other forelimb joints. Moreover, in a complex movement involving sequential activity at several joints, one would envision sequential activation of the appropriate vertical aggregates. Since each movement function is represented in multiple, separate vertical aggregates (Murphy et al., 1978), any particular movement combination is possible with the appropriate selection of horizontal clusters of such aggregates.

Access to peripheral (cf. following) or central information, carried by well documented projection systems from a variety of structures, is available. Hence, the motor cortex may receive various levels of abstraction of information concerning both the external world and the present state of the body and limbs in the world. This access to large pools of hierarchically organized information allows extreme flexibility in the ability to activate the desired cluster(s) in any particular behavioral situation.

\section{Pathological Movement:}

The Jacksonian "March"

Hughlings Jackson observed that the march phenomena which often followed the onset of a focal motor seizure typically displayed a preferred pattern of spread (Jackson, 1958). Thus, if the convulsive movement began in the hand, it would pass up the arm and down the legs; if it began in the toes, it would pass up the leg and down the arm. Similarly, focal attacks beginning in the head and neck would spread first to the shoulder, and then out to the hand. These observations have been amply confirmed in a number of case reports (cf. Walshe, 1943).

As indicated in figure 3 , the usual pattern of the march which is observed is exactly that predicted by the nested ring model of spatial organization of motor cortex. Thus, the model would predict that the ordinary manner of spread would be from the leg or head and face, through the shoulders, forearm, and to the hand, and conversely. A pattern in which the convulsive movements jumped from the toes or foot would be unusual. The earlier maps of motor cortex developed by Woolsey and colleagues (1952) are not sufficient to permit such a specific pattern of march to be predicted, although compatible with it. Thus, the degree of detail extracted by surface 
stimulation methodology allows prediction that a focal motor seizure would spread from the head or leg to arm, but the customary direction down the arm in such a case could not be predicted. Similarly, the homunculus map of motor cortex in man by Penfield and Boldrey (1937) also produced by surface stimulation, resulted in a more linear than concentric pattern, which cannot be used as a basis to predict the preferred spread of the march phenomenon as described by Jackson. The data of Leyton and Sherrington (1917) obtained by electrical stimulation of motor cortex of anthropoid primates is particularly instructive. These workers observed that the application of strong and prolonged faradization at a particular spot on the surface of motor cortex “. . . usually induces not only a considerable "march" or sequence of responsive movement, but also, as is well known, an epileptiform convulsion". Their data, presented in tabular form, is highly compatible with the preferred pattern of spread of convulsive movements in clinical seizures, and is also predicted from the nested ring model.

Although the preferential pattern of the march as described is most commonly observed, exceptions do occur (Walshe, 1943). One basis for understanding these exceptions may be the fact that there are two mechanisms by which epileptiform activity in a particular locus in motor cortex may spread. The first is by direct spread, either as a result of local depolarization associated with accumulation of extracellular potassium, and/ or by cortico-cortical connections involving synaptic mechanisms. It would be expected that such direct spread would represent a primary mechanism. A secondary mechanism might involve reverberation through functional activation of projections involving subcortical structures, particularly ventrolateral thalamus which is known to have strong reciprocal connections with motor cortex. These loops involving subcortical structures might result in activation of patches of motor cortex in unexpected ways, since axons arising in VL thalamus are known to be distributed widely in the motor cortex (Strick, 1976). Such a

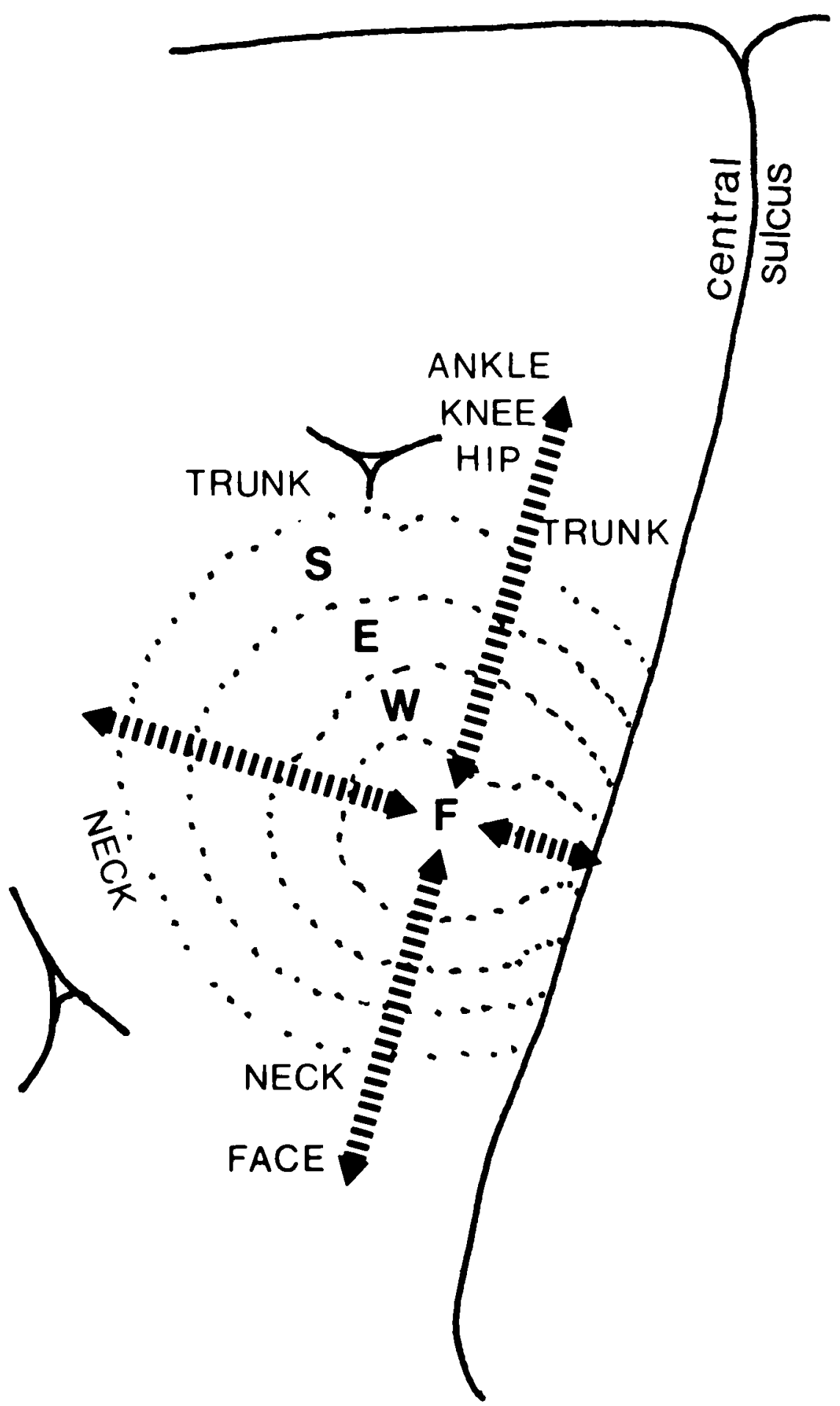

Figure 3 - The expected centrifugal pattern of spread, as predicted from the nested ring representation, is indicated. Thus convulsive movements beginning in the fingers would be expected to spread to movements about the wrist, the elbow and the shoulder, respectively, as the focus of excitation in motor cortex spread outwardly from the fingers (F) and wrist (W) areas through the nested rings representing the elbow (E) and the shoulder $(S)$ joints. This pattern would be expected irrespective of the usual direction, if any, of spread of cortical excitation. The converse march, from face and neck area or from leg area to shoulder and outward to the hand and fingers is also predicted and indicated by the arrows. 
mechanism might explain the exceptions to the preferred direction of spread of convulsive movements, and also might be related to the observation of Unverricht in 1883 that spread of convulsive movement can be maintained in a situation in which there is apparent isolation of individual cortical representations from each other (cf. Schäfer, 1900, p. 719).

\section{Influences of Peripheral Stimuli}

One of the most interesting aspects of focal motor seizures and the Jacksonian "march" concerns the influences of peripheral stimuli. A description of Gordon Holmes (1927) provides a most striking example: "... I was struck by the fact that during the prolonged examination of tactile and other forms of cutaneous sensibility over one hand, Jacksonian spasms occasionally commenced in this part in patients with cortical lesions not subject to frequent attacks. Some patients recognizing this were reluctant to submit to examination. I have frequently repeated this experiment since, and have been able, in certain cases, to induce typical local spasms in a hand or foot by repeated stimulation of it. The most effective means is usually a long or regular series of tactile contacts with a wisp of cotton-wool, a camel's hair brush, or von Frey's hairs. The attack induced usually commences with a few clonic movements, or a curious purposeless restlessness, and may extend no further if the stimulation is stopped; sometimes, however, they spread and may involve the whole of one side of the body. These movements start almost invariably in the part that is being tested; I have seen them more frequently elicited in the hand and fingers than elsewhere, probably because it is here that sensation is usually subjected to the most searching examination. As long ago as 1863 Hughlings Jackson described a case in which touching the thumb would sometimes bring on a fit, and later another case in which seizures followed testing for ankle-clonus. He also cites an observation of Brissaud's that percussion of the patellar tendon excited local epileptic attacks."

Holmes concluded that these observations provided "... . evidence that the peripheral stimulation of a limb which is subject to motor or sensory epilepsy, or of a sense organ to which analogous phenomena are referred, may excite epileptic symptoms if the corresponding part of the cortex is in an unstable state." He went on to predict "... that the inflow of a large mass of sensory impressions to the cortex raises its excitability and consequently makes it more liable to discharge if it is in an unstable state owing to the existence of injury or disease. Possibly this enhanced excitability of the cortex by peripheral stimuli in abnormal amount may explain the "reflex epilepsy" of which Brown-Sequard and his successors wrote so much ..." Holmes also made reference to the converse phenomenon, namely the arrest of focal motor seizures by the application of peripheral stimuli of various types. Corresponding observations had been made earlier (1870) by Jackson (cf. Jackson, 1958), and subsequently by Walshe (1943). One of Walshe's case reports is pertinent: "The patient volunteers this information that if, with the right forearm pronated, he taps either the lower end of the ulna or the elbow on a

A

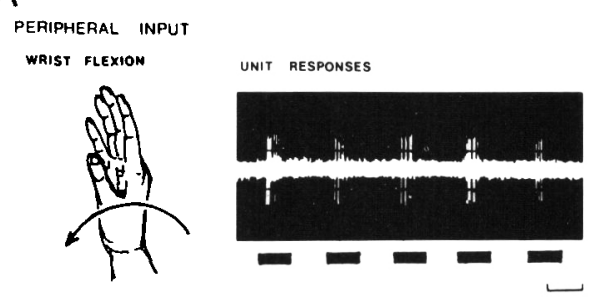

table, an attack beginning in the right hand is apt to start. Many attacks beginning spontaneously in the right hand can be cut short if he grips the right wrist firmly for several seconds with the left hand. Here rapidly recurrent stimuli appear to facilitate attacks, and prolonged sensory stimuli to abort them." An animal model which mimics many of these features has been developed by Chauvel, Lamarche and colleagues (1975 and 1978). In their experiments, an alumina cream epileptic focus was created in monkeys. Epileptic discharge from this focus could be triggered and arrested by stimulation of proprioceptive afferents, and these workers commented on the possible role of "transcortical reflexes" in producing these effects.

The prescience of Holmes is quite remarkable, as a firm physiologic basis for the above described clinical and experimental epileptic phenomena now exists. Thus, there is major evidence for input-output coupling at the level of motor cortex in subprimates such as cats (Murphy et al., 1975), and in primates (Murphy et al., 1978; Wong

B

intracortical microstimulation

Whist ExTENSOR EMG

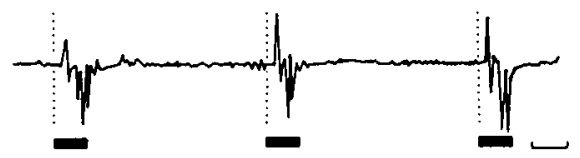

C

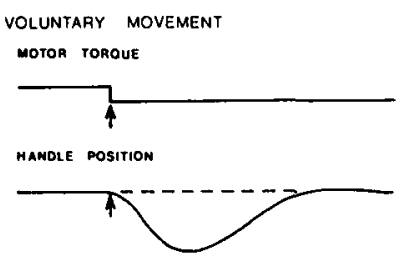

UNIT FIRING INTEAVAL FREOUENCY

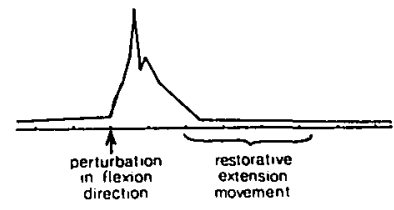

Figure 4-Input-output coupling at motor cortex. As described in the text, a single neuron in a "wrist" cluster in contralateral precentral cortex of M. speciosa discharges whenever the hand is rotated about the wrist in the flexion direction. The horizontal bars under the unit discharge indicate the application of wrist flexion. In the panel below, it is shown that ICMS at the same locus results in activation of EMG activity in a wrist extensor (surface recordings). In the panel at the right, the behavior of the same neuron at the same locus in the context of a voluntary tracking movement is shown. When the manipulandum grasped by the monkey's hand is perturbed in the flexion direction, the discharge frequency of the neuron increases. This increase is followed by a second burst which sustains the firing prior to and during the restorative extension movement. 
et al., 1978) and in humans (Goldring and Ratcheson, 1972). To adequately establish functional coupling between a particular peripheral locus and a discrete region of motor cortex, the following features are considered desirable. We have now documented each of these features in subhuman primates (M. speciosa). Firstly, in the absence of anesthesia, single neurons should be responsive to discrete proprioceptive information, such as that provided by rotation of the hand about the wrist. An example is shown in figure 4A. Secondly, ICMS at the same locus which responds to wrist flexion should produce EMG activity in wrist extensor muscles, as illustrated in figure 4B. Finally and most critically, the same neuron which responds to wrist flexion in the passive state, should be shown to function correspondingly in the course of active voluntary movement. In figure $4 C$, the same neuron as in Fig. 4A modifies its discharge appropriately in the course of a tracking task involving movement of a manipulandum with rotation of the hand about the wrist. In this case a disturbance in the flexion direction, applied by a torque motor, results in an increase of firing of the neuron. This firing is sustained and enhanced prior to a restorative movement involving extension of the hand about the wrist. This cellular behavior during voluntary movement thus exactly conforms to that predicted by the effects of passive wrist flexion and by ICMS at the same locus. Although the exact anatomic pathways for such coupling of input and output at motor cortex are not known, possibilities include the lemniscal system, and also trans-cerebellar pathways (Conrad et al., 1974; Murphy et al., 1975). These experimental observations concerning input-output coupling at motor cortex provide substantial understanding of the pathophysiology of "reflex" epilepsy.

\section{ACKNOWLEDGEMENTS}

The research described in this paper was supported by the M.R.C. of Canada. The authors are indebted to $\mathrm{Mr}$. H. Hguyen-Huu for computer programming assistance.

\section{REFERENCES}

ASANUMA, H. (1975). Recent developments in the study of the columnar arrangement of neurons within the motor cortex. Physiological Reviews, 55, 143-156.

CHAUVEL, P., LAMARCHE, M. and PUMAIN, R. (1975). Central seizures induced by proprioceptive afferents: an experimental study in the monkey. In: B.S. Meldrum and C.D. Marsden (Eds.), Advances in Neurology, vol. 10, Raven Press, New York, 129132 .

ChaUVEl, P., LOUVEL, J. and LAMARCHE, M. (1978). Transcortical reflexes and focal motor epilepsy. Electroenceph. clin. Neurophysiol. 45, 309-318.

CONRAD, B., MATSUNAMI, K., MEYERLOHMANN, J., WIESENDANGER, M. and BROOKS, V.B. (1974). Cortical load compensation during voluntary elbow movements. Brain Research, 71, 507-514.

FERRIER, D. (1876). The Functions of the Brain. Smith-Elder, London.

FETZ, E.E. and FINOCHIO, D.V. (1975). Correlations between activity of motor cortex cells and arm muscles during operantly conditioned response patterns. Exptl. Brain Research, 23, 217-240.

FRITSCH, G. and HITZIG, E. (1870). Uber die elektrische Erregbarkeit des Grosshirns. Arch. Anat. Physiol. 37, 300-332.

GOLDRING, S. and RATCHESON, R. (1972). Human motor cortex: sensory input data from single neuron recordings. Science, 175 , 1493-1495.

HOLMES, G. (1927). Local epilepsy. Lancet i, 957-962.

JACKSON, J.H. (1958). In: Selected writings of John Hughlings Jackson, vols. 1 and 2 , J. Taylor (Ed.), Basic Books, New York.

KWAN, H.C., MACKAY, W.A., MURPHY, J.T. and WONG, Y.C. (1978). Spatial organization of precentral cortex in awake primates. II. Motor outputs. J. Neurophysiol. 41, 1120-1131.

LEYTON, A.S.F. and SHERRINGTON, C.S. (1917). Observations on the excitable cortex of the chimpanzee, orang-utan, and gorilla. Q.J. Expt. Physiol. 11, 135-222.

MURPHY, J.T., KWAN, H.C., MACKAY,
W.A. and WONG, Y.C. (1978). Spatial organization of precentral cortex in awake primates. III. Input-output coupling. J. Neurophysiol. 41, 1132-1139.

MURPHY, J.T., KWAN, H.C. and WONG, Y.C. (1979). Differential effects of reciprocal wrist torques on responses of somatotopically identified neurons of precentral cortex in awake primates. Brain Research, 172. 329-337.

MURPHY, J.T., WONG, Y.C. and KWAN, H.C. (1975). Afferent-efferent linkages in motor cortex for single forelimb muscles. $J$. Neurophysiol. 38, 990-1014.

PENFIELD, W.G. and BOLDREY, E. (1937). Somatic motor and sensory representation in the cerebral cortex of man as studied by electrical stimulation. Brain, 60, 389-443.

PENFIELD, W.G. and ERICKSON, T.C. (1941). Epilepsy and Cerebral Localization. Charles C. Thomas, Springfield, III.

PHILLIPS, C.G. (1975). Laying of the ghost of 'muscles versus movement'. Can. J. Neurol. Sci. 2, 209-218.

SCHÄFER, E.A. (1900). The cerebral cortex. In: Textbook of Physiology, E.A. Schäfer (Ed.), vol. 2, pp. 697-782. Young J. Pentland, Edinburgh and London.

STRICK, Peter L. (1976). Anatomical analysis of ventrolateral thalamic input to primate motor cortex. J. Neurophysiol. 39, 1020 1031.

WALSHE, F.M.R. (1943). On the mode of representation of movements in the motor cortex, with special reference to "convulsions beginning unilaterally' (Jackson). Brain, 66 , 104-139.

WONG, Y.C., KWAN, H.C., MACKAY, W.A. and MURPHY, J.T. (1978). Spatial organization of precentral cortex in awake primates. I. Somatosensory inputs. J. Neurophysiol. 41, 1107-1119.

WONG, Y.C., KWAN, H.C. and MURPHY, J.T. (1979a). Activity of precentral neurons during torque triggered hard movements in awake primates. Can. J. Physiol. Pharmacol. 57. 174-184

WONG, Y.C., KWAN, H.C. and MURPHY, J.T. (1979b). Patterns of early and late discharges in somatotopically identified precentral neurons in awake monkeys in response to somatic inputs. Can. J. Physiol. Pharmacol. 57, 574-577.

WOOLSEY, C.N., SETTLAGE, P.H., MEYER, D.R., SENCER, W., HAMUY, T.P. and TRAVIS, A.M. (1952). Patterns of localization in precentral and "supplementary" motor areas and their relation to the concept of a premotor area. Res. Publ. Assoc. Res. Nervous Mental Diseases, 30, 238-264. 